\title{
Effects of media, working practice, and automation on the rapid detection of bacteraemia
}

\author{
JOHN E CORKILL
}

From the Department of Medical Microbiology, Royal Liverpool Hospital, Liverpool

SUMMARY Advances in the treatment of disease have resulted in an increasing number of blood cultures being processed by microbiology departments. The effect of media, revision of working hours, and automation on the time taken to detect positive cultures are reported. A $9.5 \%$ detection rate at $24 \mathrm{~h}$ with broth systems examined manually increased to $76.0 \%$ with a semiautomated radiometric technique (BACTEC). The use of radiometry in a restructured working day-that is, 9.00 am to $7.00 \mathrm{pm}$-resulted in optimum conditions for reducing the reporting time. The efficacy of modern equipment, designed to detect micro-organisms rapidly, can be considerably enhanced by reorganisation of traditional working hours to suit microbial growth rather than the current availability of staff.

Advances in the treatment of previously fatal conditions such as leukaemia, postoperative collapse, and chronic renal failure have considerably lengthened survival time of patients. Immunosuppression and the invasion of sophisticated surgery have significantly increased the incidence of bacteraemia with not only established but also many opportunist pathogens.' Clinical investigation of such episodes is now resulting in an increasing number of blood cultures being processed in microbiology laboratories (Table 1).

For the clinician, the true value of a positive blood culture is relative to the speed of reporting. In the UK rapid and accurate results are now sought in expensive laboratory automation. But, ironically, it may be the working practices adopted by many microbiologists, rather than the generation time of the microbes themselves, which determine the reporting time. A greater flexibility of laboratory working hours, aligned to shorter incubation periods - that is, 8-12 $\mathrm{h}$-rather than the conventional long overnight incubation-18-24 h-may equally contribute to a reduction in the reporting time.

In an attempt to address the challenge of rapidly servicing the blood culture requirements for an 820 bed district general hospital (teaching), the effects of either broth or biphasic media, revision of working hours, and automation were studied over a five year period, encompassing about 14000 samples.

Accepted for publication 8 November 1984

\section{Material and methods}

\section{REPORTING TIME}

By convention, reports from most laboratories identify blood cultures as being positive at the time a particular subculture was performed. Such reporting fails to account for the delay occasioned by the incubation of this subculture and therefore conceals a protracted reporting time. A more meaningful reporting time should be defined as the period from the collection of specimen to the moment a report, microscopy or culture, reaches the clinician. Positive blood cultures in all methods were either direct conclusive microscopy or culture.

Table 1 Numbers of blood culture sets examined by the microbiology department for the past 12 years

\begin{tabular}{lc}
\hline Year & Blood culture sets* \\
\hline 1972 & 740 \\
1973 & 808 \\
1974 & 1013 \\
1975 & 944 \\
1976 & 938 \\
1977 & 1170 \\
1978 & 1436 \\
1979 & 2196 \\
1980 & 2403 \\
1981 & 2995 \\
1982 & 3258 \\
1983 & 4311 \\
\hline
\end{tabular}

1972-8 = Liverpool Royal Infirmary, 350 beds. 1979-83 = Royal Liverpool Hospital, 850 beds. ${ }^{*}$ Two vials per set. 
CRITERIA FOR STUDY

The following criteria were applied to aid interpretation of the laboratory findings:

1 First positive finding only was recorded, from either aerobic or anaerobic vial.

2 For bacteraemia, all recurring isolates from the same patient found in the next seven days were excluded.

3 For fungaemia, only the first isolation was scored.

In the study both coagulase negative, catalase positive Gram positive cocci and coryneforms were excluded in an attempt to include in this analysis only bacteria likely to have originated in the blood stream, rather than possible skin or laboratory contaminants. Such micro-organisms, however, are incriminated as pathogens in the compromised host.

\section{CONVENTIONAL BROTH SYSTEM (9.00 am}

examination)

For many years the department traditionally employed a two bottle system: digest broth (containing $0.1 \% \mathrm{wt} / \mathrm{vol}$ glucose) and cooked meat medium (both supplied by Southern Group Laboratory). Specimens were processed daily (9.00 am) and subcultured on to horse blood agar (Lab M Ltd) aerobically and anaerobically and examined 24 and $48 \mathrm{~h}$ later. Direct microscopy, by Gram stain, was performed only on bottles showing macroscopic changes (gas production or red cell lysis/darkening or both).

BIPHASIC SYSTEM (9.00 am examination)

In 1979 a new blood culture system was introduced, which comprised a biphasic brain-heart infusion broth/agar slant (Gibco Europe Ltd) and fastidious anaerobe broth, a chemically defined medium (Lab M Ltd). The agar slant of the aerobic biphasic bottle was macroscopically examined daily (9.00 am) for bacterial growth, and the anaerobic broth subcultured in the traditional manner. Again, direct microscopy was performed only on bottles showing macroscopic changes, as described above.

CONVENTIONAL BROTH SYSTEM (9.00 am and $9.00 \mathrm{pm})$

The withdrawal, by Gibco Ltd, of the biphasic bottle required the introduction of a new system; brain- heart infusion broth and fastidious anaerobe broth (both Lab M). Also, the working hours in the laboratory were restructured to include a second examination in the evening $(9.00 \mathrm{pm})$. This scheme offered two main advantages:

1 All new blood cultures, collected between midnight and $4.00 \mathrm{pm}$ that day, reported as $<16 \mathrm{~h}$ old, can be subcultured before the following morning. By tradition such specimens are normally preincubated for at least $24 \mathrm{~h}$ before subculture.

2 Specimens already subcultured that morning may be examined and reported on without further delay.

\section{RADIOMETRY}

Method 1 (9.00 am, 4.00 pm, and 9.00 pm)

In 1982 a study of a semiautomated radiometric (carbon-14) blood culture system (BACTEC, model 460 , Johnston Laboratories, USA) was initiated. The manufacturers recommended threshold growth index (GI) of $>30$ for the aerobic vial (enriched tryptic soy broth) resulted in an unacceptable high number of biological false positive cultures (raised GI, but negative culture). The detection sensitivity was therefore reduced to a GI of $>40$. A GI of $>40$ for the aerobic vial together with conclusive microscopy was recorded as positive. Similarly, a GI of $>18$ for the anaerobic vial (prereduced trypic soy broth) more often discriminated between true and false positive anaerobic cultures. Terminal subcultures were not performed.

\section{Method 2 (9.00 am and $7.00 \mathrm{pm}$ )}

After 12 months' evaluation of method 1, a further reduction of the reporting time was attempted through a modified examination schedule (Table 3 ). The first examination of the anaerobic vial was now performed on day 1 ( $24 \mathrm{~h}$ earlier than recommended by the manufacturers) to detect specifically facultative anaerobes. The afternoon examination of the aerobic vials (previously at $4.00 \mathrm{pm}$ ) was now performed later in the evening $(7.00 \mathrm{pm})$.

\section{ORGANISMS}

Identification of all isolates was confirmed using a combination of standard methods ${ }^{2}$ and commercial identification kits (from API Labs and Becton Dickinson Ltd).

Table 2 Radiometric method 1: sampling schedule

\begin{tabular}{|c|c|c|c|c|c|c|}
\hline & $\leqslant 16 h$ & $24 h$ & $48 h$ & $72 h$ & 5 days & 10 days \\
\hline $\begin{array}{l}\text { Aerobic } \\
\text { Anaerobic }\end{array}$ & 9.00 & $\begin{array}{l}9.00 \mathrm{am} \\
4.00 \mathrm{pm}\end{array}$ & $\begin{array}{l}9.00 \mathrm{am} \\
4.00 \mathrm{pm} \\
9.00 \mathrm{am}\end{array}$ & $\frac{9.00 \mathrm{am}}{9.00 \mathrm{am}}$ & $\frac{9.00 \mathrm{am}}{9.00 \mathrm{am}}$ & $\frac{9.00 \mathrm{am}}{9.00 \mathrm{am}}$ \\
\hline
\end{tabular}


Table 3 Radiometric method 2: sampling schedule

\begin{tabular}{lllllll}
\hline & $\leqslant 16 h$ & $24 h$ & $48 h$ & $72 h$ & 5 days & 10 days \\
\hline Aerobic & $7.00 \mathrm{pm}$ & $9.00 \mathrm{am}$ & $9.00 \mathrm{am}$ & $9.00 \mathrm{am}$ & $9.00 \mathrm{am}$ & $9.00 \mathrm{am}$ \\
Anaerobic & & $9.00 \mathrm{am}$ & $9.00 \mathrm{am}$ & $9.00 \mathrm{am}$ & $9.00 \mathrm{am}$ & $9.00 \mathrm{am}$ \\
\hline
\end{tabular}

Table 4 Percentage of positive blood cultures and their reporting times for four diagnostic systems

\begin{tabular}{|c|c|c|c|c|c|c|c|}
\hline \multirow[t]{2}{*}{ Method } & \multirow[t]{2}{*}{ No of infective episodes* } & \multicolumn{6}{|c|}{ Percentage of infective episodes reported at } \\
\hline & & $\leqslant 16 h$ & $24 h$ & $48 h$ & $72 h$ & 5-7 days & 10-14 days \\
\hline \multirow{4}{*}{$\begin{array}{l}\text { Digest broth } \\
\text { Cooked meat broth } \\
\text { Biphasic brain-heart } \\
\text { Fastidious anaerobe broth } \\
\text { Brain-heart infusion } \\
\text { Fastidious anaerobe broth } \\
\text { Radiometry-method } 1 \\
\text { Radiometry-method } 2\end{array}$} & 159 & ND & $9 \cdot 5$ & $63 \cdot 9$ & $13 \cdot 9$ & $9 \cdot 8$ & $2 \cdot 8$ \\
\hline & 176 & ND & $21 \cdot 4$ & 50.0 & $16 \cdot 4$ & $6 \cdot 4$ & $5 \cdot 7$ \\
\hline & 249 & $2 \cdot 8$ & $13 \cdot 9$ & $48 \cdot 2$ & $17 \cdot 7$ & $12 \cdot 7$ & $4 \cdot 6$ \\
\hline & $\begin{array}{l}298 \\
329\end{array}$ & $\begin{array}{l}4 \cdot 4 \\
5 \cdot 6\end{array}$ & $\begin{array}{l}48 \cdot 2 \\
70 \cdot 4\end{array}$ & $\begin{array}{l}36 \cdot 0 \\
16 \cdot 1\end{array}$ & $\begin{array}{l}4 \cdot 8 \\
3 \cdot 2\end{array}$ & $\begin{array}{l}2.5 \\
2.9\end{array}$ & $\begin{array}{l}4.0 \\
1.6\end{array}$ \\
\hline
\end{tabular}

*Number of bottles taken per infective episode varied.

ND $=$ not done

\section{Results}

The percentages of infective episodes reported at various times for each of the four diagnostic systems studied (over a typical 12 month period), are summarised in Table 4. Owing to variations in the four sampling schedules, blood cultures which became positive later than $72 \mathrm{~h}$ have been combined in the last two columns. In the course of this study the percentage of positive blood cultures reported at $24 \mathrm{~h}$ increased from $9.5 \%$ to $76.0 \%$, an eightfold increase in reporting time. The introduction of a second examination at $9.00 \mathrm{pm}$ alone increased the rate of positive blood cultures obtained through the non-automated methods from $9.5 \%$ to $16.7 \%$ within $24 \mathrm{~h}$.

A detailed analysis of reporting times obtained with the radiometric system are presented in the Figure and Table 5; the percentage of infective episodes at $24 \mathrm{~h}$ and $48 \mathrm{~h}$ diagnosed at the morning, afternoon, and evening examinations are noted. With radiometry (method 1$), 52.6 \%$ of all infective episodes were reported within $24 \mathrm{~h}$, compared with $9.5 \%, 21.4 \%$, and $16.7 \%$ respectively from the three conventional systems. Although operating the radiometric system (method 1) with two examinations on day 1 increased the detection of infective episodes from $38.4 \%$ to $48.2 \%$, on day 2 the increase was less than $1 \%$. With the radiometric system (method 2) $76.0 \%$ of all infective episodes were reported within $24 \mathrm{~h}$, a $23.4 \%$ improvement over method 1 . Of $53.3 \%$ of positive blood cultures diagnosed in the morning of day 1 (method 2$), 47.7 \%$ originated from the aerobic vials and $5.6 \%$ from the anaerobic.

Performance of the first 507 infective agents detected by radiometry (combined methods 1 and 2) are shown in Tables 6 and 7. Major bacterial groups are reported in Table 6 and some chosen individual pathogens in Table 7.

\section{Discussion}

The ability to detect microbial growth rapidly must be an important determinant of the efficacy of a blood culture system. As increasing numbers of blood cultures, ${ }^{3}$ initiated by clinicians, place tremendous pressure on laboratory resources, alternative techniques must be investigated. Traditional methods are labour intensive and require the skill of more senior staff to minimise the risk of specimens

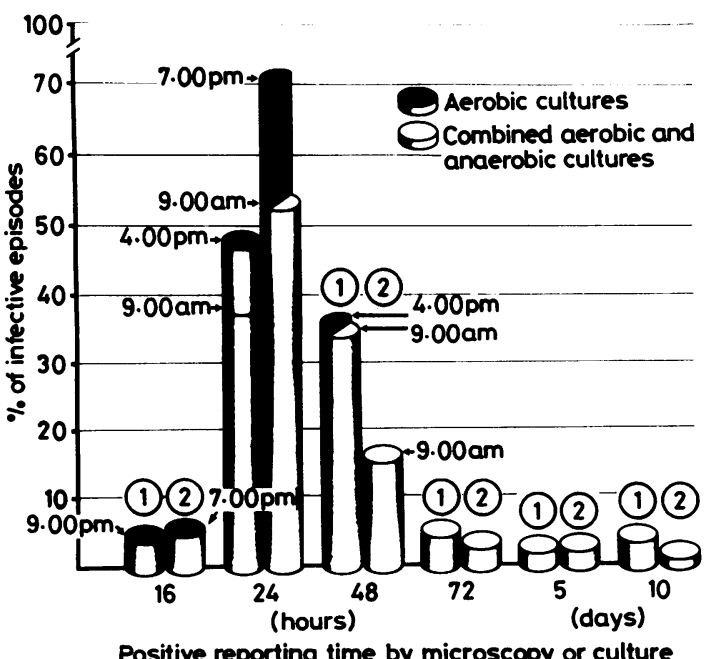

Comparison of positive reporting times for sampling methods 1 and 2 with an automated radiometric $\left(C^{14}\right)$ blood culture system (BACTEC). 
Table 5 Radiometry, methods 1 and 2: percentage of positive blood cultures detected at various sampling and reporting times

\begin{tabular}{|c|c|c|c|c|c|c|c|}
\hline & Sampling time & $\leqslant 16 h$ & $24 h$ & $48 h$ & $72 h$ & 5 days & 10 days \\
\hline \multirow[b]{2}{*}{ Method 1} & $9.00 \mathrm{am}$ & - & $38 \cdot 4$ & $35 \cdot 1$ & $4 \cdot 8$ & $2 \cdot 5$ & $4 \cdot 0$ \\
\hline & $\begin{array}{l}4.00 \mathrm{pm} \\
9.00 \mathrm{pm}\end{array}$ & $\overline{4 \cdot 4}$ & $9 \cdot 8$ & 0.9 & - & - & - \\
\hline & & & & & & - & - \\
\hline \multirow{3}{*}{ Method 2} & Iotal & & $48 \cdot 2$ & 36.0 & $4 \cdot 8$ & 2.5 & $4 \cdot 0$ \\
\hline & $\begin{array}{l}9.00 \mathrm{am} \\
7.00 \mathrm{pm}\end{array}$ & $\overline{5 \cdot 6}$ & $\begin{array}{l}53.3 \\
17.1\end{array}$ & $16 \cdot 1$ & $3 \cdot 2$ & $2 \cdot 9$ & 1.6 \\
\hline & Total & $5 \cdot 6$ & & $16 \cdot 1$ & $3 \cdot 2$ & 2.9 & 1.6 \\
\hline
\end{tabular}

- = sampling not performed.

being contaminated during handling. Since blood cultured with a biphasic technique or radiometry is disturbed less often, the likelihood of laboratory contamination is proportionally reduced, despite frequent daily examinations. Lower numbers of contaminants increase the laboratory's confidence in commenting on their potential importance. It is unrealistic, however, to expect rapid automated systems to be capable of differentiating between genuine pathogens and skin contaminants.

In most clinical specimens bacteria are normally detected by isolation on solid media. This is a slow process requiring $24-48 \mathrm{~h}$ incubation. Alternatively, automated methods are designed to detect bacteria biochemically. Examples include bacterial ATPase, ${ }^{4}$ countercurrent immunoelectrophoresis, ${ }^{5}$ impediometry, ${ }^{6}$ and radiometry, ${ }^{7}$ followed by conclusive microscopy. Such findings do not always identify infecting micro-organisms, but they do direct the microbiologist's attention to positive samples requiring further investigation and the clinician towards initiating empirical antimicrobial treatment.

Conventionally, when the microscopical examination of a blood culture is conclusive a report is relayed to the ward immediately, and the episode is scored as positive on the same day. When microscopy is negative the specimens are subcultured and re-examined after $24 \mathrm{~h}$ incubation. If, on examining this subculture $24 \mathrm{~h}$ later, growth is noted, the results are reported again immediately. Hence, while such positive cultures are in fact reported to the ward at least $48 \mathrm{~h}$ after venepuncture, the microbiologist will often score these findings as having originated at $24 \mathrm{~h}$. As a result of this widespread modus operandi such "reporting time" is always $24 \mathrm{~h}$ shorter than the actual time when the clinician became aware of the results.

The introduction of a biphasic system produced results more quickly at $24 \mathrm{~h}(21.4 \%)$ than the previous method $(9.5 \%)$. In practice, however, this system did not satisfactorily isolate and maintain pneumococci. This deficiency together with frequent contamination during manufacture resulted in a return to a two bottle broth system, brain-heart infusion and fastidious anaerobe broth. Also, the working practices of the laboratory were restructured to include a second examination of specimens in the evening $(9.00 \mathrm{pm})$, which resulted in a $16.7 \%$ positive detection rate at $24 \mathrm{~h}$ compared with $9.5 \%$ with the previous all broth system.

With the exception of the early examination (< $16 \mathrm{~h}$ ), the choice of sampling times for radiometry (method 1, Table 2) was as recommended by the manufacturer. After the data presented in Table 5 became available, an attempt to reduce the reporting time even further was made. This revised sampling procedure, outlined in Table 3 , was designed specifically to suit the particular requirements of patients at the Royal Liverpool Hospital and availability of laboratory personnel and may prove difficult to implement in establishments smaller than ours.

Table 6 Isolation times of major bacterial groupings by a radiometric blood culture system

\begin{tabular}{|c|c|c|c|c|c|c|c|}
\hline \multirow[t]{2}{*}{ Bacterial group } & \multirow{2}{*}{$\begin{array}{l}\text { No of } \\
\text { isolations }\end{array}$} & \multicolumn{6}{|c|}{$\%$ positive isolations found at } \\
\hline & & $\leqslant 16 h$ & $24 h$ & $48 h$ & $72 h$ & 5 days & 10 days \\
\hline $\begin{array}{l}\text { Gram negative bacilli } \\
\text { Streptococci } \\
\text { Staphylococcus aureus } \\
\text { Pseudomonas spp } \\
\text { Fungi } \\
\text { Anaerobes } \\
\text { Miscellaneous bacteria } \\
\text { Overall performance }\end{array}$ & $\begin{array}{r}218 \\
99 \\
77 \\
43 \\
34 \\
28 \\
8 \\
507\end{array}$ & $\begin{array}{r}10 \\
12 \\
7 \\
5 \\
0 \\
0 \\
0 \\
8\end{array}$ & $\begin{array}{l}64 \\
70 \\
68 \\
56 \\
23 \\
21 \\
25 \\
60\end{array}$ & $\begin{array}{l}20 \\
16 \\
21 \\
26 \\
59 \\
40 \\
12 \cdot 5 \\
24\end{array}$ & $\begin{array}{r}2 \\
1 \\
2 \\
12 \\
6 \\
18 \\
50 \\
5\end{array}$ & $\begin{array}{c}2 \\
1 \\
2 \\
1 \\
12 \\
11 \\
12 \cdot 5 \\
3\end{array}$ & 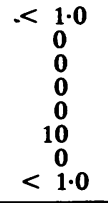 \\
\hline
\end{tabular}


Table 7 Isolation times of bacteria by a radiometric blood culture system

\begin{tabular}{|c|c|c|c|c|c|c|c|}
\hline \multirow[t]{2}{*}{ Organism } & \multirow{2}{*}{$\begin{array}{l}\text { Total no of } \\
\text { isolations }\end{array}$} & \multicolumn{6}{|c|}{$\%$ positive isolations found at } \\
\hline & & $\leqslant 16 h$ & $24 h$ & $48 h$ & $72 h$ & 5 days & 10 days \\
\hline $\begin{array}{l}\text { Streptococcus pneumoniae } \\
\text { Faecal type streptococci } \\
\text { Escherichia coli } \\
\text { Staphylococcus aureus } \\
\text { Aeromonas hydrophilia }\end{array}$ & $\begin{array}{r}24 \\
43 \\
133 \\
77 \\
5\end{array}$ & $\begin{array}{r}21 \\
12 \\
10 \\
7 \\
60\end{array}$ & $\begin{array}{l}67 \\
81 \\
64 \\
68 \\
40\end{array}$ & $\begin{array}{r}12 \\
7 \\
21 \\
21 \\
0\end{array}$ & $\begin{array}{l}0 \\
0 \\
2 \\
2 \\
0\end{array}$ & $\begin{array}{l}0 \\
0 \\
3 \\
2 \\
0\end{array}$ & $\begin{array}{c}0 \\
0 \\
<1 \cdot 0 \\
0 \\
0\end{array}$ \\
\hline
\end{tabular}

Afternoon sampling of aerobic cultures with the first radiometric method (about 6-7 $\mathrm{h}$ after the morning analysis) resulted in the detection of an additional $9.8 \%$ positive specimens on day 1 (Table 5). In an attempt to increase further the detection rate, the afternoon examination was replaced by a new early evening time of $7.00 \mathrm{pm}(\operatorname{method} 2,11 \mathrm{~h}$ after the morning analysis). The aim was to detect some of the positive samples previously found the next morning on day 2 (morning examination). This alteration resulted in a $17 \cdot 1 \%$ detection rate, compared with $9.8 \%$ under method 1 . Owing to the increased workload of the on call staff after normal hours, the original $9.00 \mathrm{pm}$ examination was brought forward to the new time of $7.00 \mathrm{pm}$. Table 5 (method 1) indicates that only a small proportion of bacteria are found from the aerobic cultures during the afternoon examination of day $2(<1.0 \%$ increased), and this practice was therefore discontinued (method 2).

A not unexpected finding which emerged through radiometry (method 1) was the detection of an appreciable number of facultative anaerobic bacteria only in the anaerobic vials, possibly a result of low numbers of pathogens in the patients' blood. First examination of anaerobic cultures at $48 \mathrm{~h}$ was according to the manufacturer's instructions. Processing these cultures $24 \mathrm{~h}$ earlier (method 2) for facultative anaerobic bacteria, however, resulted in $5.6 \%$ isolation from these cultures alone. Recently, Johnson Laboratories have formulated an improved anaerobic medium (7D) to be examined at $24 \mathrm{~h}$, as already practised here.

Examining the traditional blood cultures twice a day (morning and afternoon) doubled the detection rate. When the interval between the two daily examinations of the radiometric system was increased to $11 \mathrm{~h}$, however, the rate of detection also increased from $52.6 \%$ to $76.0 \%$. On this occasion the early sampling of the anaerobic culture and the extended working hours together contributed to an increased detection rate at $24 \mathrm{~h}$. Thus, an additional $23.4 \%$ of all infective episodes were reported after collection of specimens: a significant reduction in the overall reporting time.

The performances of radiometric techniques for major bacterial groupings and individual pathogens are illustrated in Tables 6 and 7. Rapid detection, that is $<16 \mathrm{~h}$, was not shown for the more fastidious pathogens such as obligate anaerobes and fungi. Positive detection at $<16 \mathrm{~h}$ was more commonly associated with immune compromised patients; all five Aeromonas hydrophila infections presented in patients with leukaemia.

Time is the crucial factor which determines the usefulness of laboratory reports to the clinician. A major advantage of automated over manual procedures is their ability rapidly to detect microbial activity. With the classic digest broth/cooked meat system, only $9.5 \%$ of all infective episodes were reported to the clinicians at $24 \mathrm{~h}$. The combination of biphasic brain-heart/fastidious anaerobe broth system doubled the detection rate, while the introduction of radiometry resulted in $76.0 \%$ of all episodes being reported within this same time period.

To maximise fully the contribution of such rapid diagnostic procedures to the patient's treatment the working practices in the laboratory must be reviewed: to eliminate the unnecessarily long incubation periods findings must be responded to immediately, regardless of whether such response has to take place after the convenient "normal hours."

\section{References}

' Louria DB. Superinfection: A partial overview. In: Prier JE, Friedman H, eds. Opportunistic Pathogens. London: MacMillan Press, 1974:1-18.

${ }^{2}$ Cowan ST, Steel KJ. Manual for the identification of medical bacteria. 2nd ed. Cambridge: Cambridge University Press, 1974.

${ }^{3}$ Gould JC, Duerden BI. Blood culture-current state and future prospects. J Clin Pathol 1983;36:963-77.

${ }^{4}$ Schrock CG, Barza MJ, Deming JW, Picciolo GL, Chapelle EW, Weinstein L. Rapid detection of bacterial growth in blood by means of adenosine triphosphate determination. In: Abstracts of the American Society for Microbiology. Annual Meeting, 1976. paper no C71:37.

s Simpson RA, Speller DCE. Detection of bacteraemia by countercurrent electrophoresis. Lancet 1977; i: 1206.

- Buckland A, Kessock-Philip S, Bascomb S. Early detection of bacterial growth in blood culture by impedance monitoring with a Bactometer model 32. J Clin Pathol 1983;36:823-8.

' DeBlanc HJ Jnr, Deland F, Wagner HN Jnr. Automated radiometric detection of bacteria in 2967 blood cultures. Appl Microbiol 1981;22:846-9.

Requests for reprints to: Mr John Edward Corkill, Department of Medical Microbiology, Royal Liverpool Hospital, Prescot Street, Liverpool L7 8XP, England. 